\title{
Further Evidence that Shallot Yellow Stripe Virus (SYSV) Is a Distinct Potyvirus and Reidentification of Welsh Onion Yellow Stripe Virus as a SYSV Strain
}

\author{
R. A. A. van der Vlugt, P. Steffens, C. Cuperus, E. Barg, D.-E. Lesemann, L. Bos, and H. J. Vetten
}

First, third, and sixth authors: DLO Research Institute for Plant Protection (IPO-DLO), P.O. Box 9060, NL-6700 GW Wageningen, the Netherlands; and second, fourth, fifth, and seventh authors: Biologische Bundesanstalt für Land- und Forstwirtschaft (BBA), Institut für Pflanzenvirologie, Mikrobiologie und Biologische Sicherheit, Messeweg 11-12, D-38104 Braunschweig, Germany. Accepted for publication 16 October 1998.

\begin{abstract}
van der Vlugt, R. A. A., Steffens, P., Cuperus, C., Barg, E., Lesemann, D.-E., Bos, L., and Vetten, H. J. 1999. Further evidence that shallot yellow stripe virus (SYSV) is a distinct potyvirus and reidentification of Welsh onion yellow stripe virus as a SYSV strain. Phytopathology 89:148-155.

An antiserum to shallot yellow stripe virus (SYSV) was raised and used in combination with a range of other antisera to potyviruses of Allium spp. in electron microscopic decoration experiments. The serological results corroborated an earlier finding that the type isolates of SYSV and Welsh onion yellow stripe virus (WoYSV) are closely related to each other and only distantly related to onion yellow dwarf (OYDV) and leek yellow stripe (LYSV) viruses, the two other major potyviruses infecting Allium spp. Moreover, the decoration results indicated that Japanese potyviruses
\end{abstract}

ABSTRACT named OYDV and Wakegi yellow dwarf virus are isolates of SYSV. Sequence analysis of the $3^{\prime}$-terminal regions of the SYSV and WoYSV genomes revealed coat protein $(\mathrm{CP})$ amino acid and $3^{\prime}$-nontranslated region ( $3^{\prime}$-NTR) nucleotide sequence identities of 95 and $89 \%$, respectively. The $\mathrm{CP}$ amino acid and 3'-NTR nucleotide sequences of these viruses differed from those of OYDV and LYSV by $>25$ and $>67 \%$, respectively. The serological and molecular studies showed that SYSV and WoYSV are different strains of a potyvirus distinct from OYDV and LYSV. For priority reasons, we propose that these strains together with the Wakegi-type isolates of OYDV described in Japan be referred to as SYSV and that SYSV isolates from Allium spp. other than shallot be designated as the Welsh onion strain of SYSV (SYSV-Wo).
Viruses of Allium spp. $(7,36)$ have attracted considerable attention in recent years. Those of garlic and shallot are especially topical internationally, because these crops are of great economic importance and their vegetative propagules are distributed worldwide. Several of the viruses that infect Allium spp., such as certain carlaviruses (29) and mite-borne filamentous viruses $(32,33)$, generally induce no or only mild symptoms. However, the aphid-borne potyviruses (28) usually cause distinct symptoms and are considered economically important in Allium spp. crops. Onion yellow dwarf (OYDV) and leek yellow stripe (LYSV) viruses have been characterized earlier as distinct potyviruses because of their specialization on different natural hosts (onion and leek, respectively), characteristic symptoms on experimental hosts, and relatively distant serological relationships (8). Investigations on potyvirus isolates from numerous samples of Allium spp. of botanically and geographically diverse origin led Van Dijk (28) to distinguish two new aphid-borne potyviruses, namely shallot yellow stripe (SYSV) and Welsh onion yellow stripe (WoYSV) viruses, specialized on shallot (A. cepa var. ascalonicum Backer) and Welsh onion (A. fistulosum L.), respectively.

SYSV was isolated from shallot samples originating from southeast Asia (Indonesia, China, and Thailand), where it appears to be common. It did not infect leek (A. ampeloprasum L. var. porrum (L.) Gay), Welsh onion, Chenopodium spp., and Nicotiana spp.; was infectious to onion 'Crystal Wax', which is resistant to most isolates of OYDV; and did not react with the Dutch antisera to OYDV and LYSV. WoYSV was found to be serologically related to SYSV and distantly related to OYDV, but different from these

Corresponding author: R. A. A. van der Vlugt;

E-mail address: R.A.A.vanderVlugt@ipo.dlo.nl

Publication no. P-1998-1209-03R

(C) 1999 The American Phytopathological Society and other potyviruses in its pathogenicity to rakkyo (A. chinense G. Don) and Welsh onion (28). Since no antisera to formally described isolates of SYSV and WoYSV were available in the former studies, further serological tests were suggested (28) to clarify the taxonomic difference between SYSV and WoYSV.

Based on sequence data for potyviruses present in botanically and geographically diverse samples of Allium spp., Tsuneyoshi et al. (24) have recently provided evidence for the occurrence of three distinct groups of potyvirus isolates from Allium spp. Two of them were assigned to OYDV and LYSV based on high levels of coat protein (CP) amino acid sequence identities to OYDV and LYSV isolates studied elsewhere. They proposed the name Wakegi yellow dwarf virus (WYDV) for a group of closely related potyvirus isolates from shallot, rakkyo, Welsh onion, and Wakegi onion $(A$. wakegi Araki) in Japan and Indonesia, although they pointed to the similarity of the WYDV isolates to Indonesian isolates of SYSV and WoYSV described earlier by Van Dijk (28). No attempts were made to characterize the WYDV isolates biologically and serologically or to compare them with Van Dijk's SYSV and WoYSV isolates.

We have now purified virions of SYSV and produced a specific antiserum to serologically characterize this virus as a distinct potyvirus. The relationships between SYSV, WoYSV, and other potyviruses of Allium spp. were also studied at the molecular level by determining and comparing the nucleotide sequences of the $\mathrm{CP}$ gene and 3'-nontranslated region (3'-NTR) of their RNAs.

\section{MATERIALS AND METHODS}

Virus isolates. The virulent SYSV isolate Ac127I originated from a shallot sample from Sumenep, Java (28), and the WoYSV isolate Af19I from a severely diseased crop of Welsh onion 'Papak' at Ciwidey, Java, Indonesia $(28,30,31)$. The SYSV isolates 642Sh 
and 318Sh, originating from shallot plants in Thailand and Taiwan, respectively, and the WoYSV isolates 7WO and 198WO, both collected from Welsh onion in Taiwan, were maintained in the original host plant by vegetative propagation. The OYDV isolate Ac41, previously described by Bos et al. (8), was from the DLO Research Institute for Plant Protection (IPO-DLO) plant virus collection. With the exception of the LYSV isolate 510L, all OYDV and LYSV isolates from the plant virus collections at IPODLO and Biologische Bundesanstalt für Land- und Forstwirtschaft (BBA) were maintained by sap inoculation onto onion ('Stuttgarter Riesen') and leek ('Jolant') seedlings, respectively, under aphidfree conditions in the glasshouse at $22^{\circ} \mathrm{C}$ as previously described (28). The LYSV isolate from leek in Singapore (510L) was maintained in Chenopodium quinoa by mechanical inoculation.

Virion purification. Virions of SYSV Ac127I were purified from sap-inoculated 'Stuttgarter Riesen' onion plants showing typical yellow stripe symptoms (28). After homogenization of frozen leaf material in McIlvaine's sodium citrate buffer $(0.18 \mathrm{M}, \mathrm{pH} 7)$ containing $0.01 \mathrm{M}$ sodium thioglycolate and $0.02 \mathrm{M}$ sodium diethyldithiocarbamate, the homogenate was stirred overnight at $4^{\circ} \mathrm{C}$ with $1 \%$ Triton $\mathrm{X}-100$, filtered through cheesecloth, and differentially centrifuged at $10,000 \times g$ for $10 \mathrm{~min}, 77,000 \times g$ for $1.5 \mathrm{~h}, 10,000 \times$ $g$ for $10 \mathrm{~min}$, and $35,000 \times g$ for $1.5 \mathrm{~h}$. After resuspension of the pellet and low-speed centrifugation, the supernatant was subjected to sucrose density-gradient centrifugation (10 to $40 \%$; $2 \mathrm{~h}$ at $83,000 \times g$ ). Virion-containing fractions were concentrated by highspeed centrifugation $(3 \mathrm{~h}$ at $126,000 \times g)$ followed by two cycles of quasi-isopycnic centrifugation in $397 \mathrm{mg}$ of $\mathrm{CsCl}$ per $\mathrm{ml}(22 \mathrm{~h}$ at $111,000 \times g$ ). Resulting virion-containing fractions were dialyzed against McIlvaine's buffer mixed with glycerol (1:1) and stored at $-20^{\circ} \mathrm{C}$.

Preparation of antiserum. Rabbits were immunized by administering, at 4-week intervals, three consecutive subcutaneous injections containing purified virions $(0.5 \mathrm{mg})$ emulsified in Freund's incomplete adjuvant. A final booster injection of purified virions $(0.25 \mathrm{mg})$ emulsified in the same adjuvant was given subcutaneously 3 months after the last injection. Rabbits were bled before and after the final booster injection. The immunoglobulin $\mathrm{G}$ (IgG) fraction was purified according to standard methods.

Electron microscopic decoration experiments and sources of antibodies. Decoration tests were performed at BBA, Braunschweig, essentially as described by Vetten et al. (35). The monoclonal antibody (MAb) 1H12 raised against SYSV Ac127I as well as the antisera to OYDV 510 and LYSV isolates from leek (LBBA) and garlic (512G) were from the stock of BBA, Braunschweig. Antisera to SYSV Ac127I (described above), an onion isolate (Ac41) of OYDV, and a leek (Aa22) isolate of LYSV were from the stock of IPO-DLO, Wageningen. Antisera to an onion isolate of OYDV, OYDV-Fukami, OYDV-O, and WYDV, were provided by H. Lot (Montfavet, France), M. Fukami (Chiba, Japan), S. T. Ohki (Osaka, Japan) (18), and S. Sumi (Hiroshima, Japan), respectively.

Cloning and sequencing of SYSV Ac127I at BBA, Braunschweig. For cloning and sequencing of the $3^{\prime}$ end of the SYSV genomic RNA, viral RNA was extracted from purified virions of SYSV isolate Ac127I and used for oligo(deoxyribosylthymine [dT])-primed cDNA synthesis and cloning into a Bluescript $\mathrm{pSK}^{-}$vector essentially as described by Maiss et al. (16). This resulted in a number of clones with inserts of up to 2,000 bp whose terminal parts were sequenced for obtaining tentative sequence data. Only clones containing a poly(A) tail were further analyzed by primer-walking to obtain overlapping sequence information for the $3^{\prime}$ end of the SYSV genome. All recombinant DNA techniques were performed as specified by Sambrook et al. (19). Sequencing of selected clones was done on double-stranded DNA templates according to Sanger et al. (20). Sequence data were compiled and analyzed with UW-GCG (version 8; Genetic Computer Group, Inc., Madison, WI).
Immunocapture reverse transcriptase polymerase chain reaction (RT-PCR). Eppendorf tubes $(0.7 \mathrm{ml})$ were coated with $100 \mu \mathrm{l}$ of anti-SYSV IgG $(2 \mu \mathrm{g} / \mathrm{ml})$ in phosphate-buffered saline (PBS) for $3 \mathrm{~h}$ at $37^{\circ} \mathrm{C}$, followed by three washings with PBS. Thereafter, virions were trapped by overnight incubation of tubes at $4^{\circ} \mathrm{C}$ with $200 \mu \mathrm{l}$ of leaf extracts (100 mg/ml of PBS) from 'Stuttgarter Riesen' onion when showing clear SYSV symptoms $\sim 3$ weeks after sap inoculation. Unbound leaf material was removed by washing the tubes three times with PBS. Excess liquid was carefully removed after the last washing step. Prior to cDNA synthesis, trapped virus particles were denatured by adding $8 \mu$ of $5 \times$ First Strand Buffer (Life Technologies, Inc., Gaithersburg, MD), $1 \mu \mathrm{l}$ of first-strand primer $(100 \mathrm{ng} / \mu \mathrm{l})$, and $21 \mu \mathrm{l}$ of $\mathrm{H}_{2} \mathrm{O}$, followed by incubation of the tube at $65^{\circ} \mathrm{C}$ for $5 \mathrm{~min}$. Thereafter, cDNA was synthesized by adding $4 \mu \mathrm{l}$ of $\mathrm{H}_{2} \mathrm{O}, 4.5 \mu \mathrm{l}$ of $0.1 \mathrm{M}$ dithiothreitol (Life Technologies, Inc.), $1 \mu$ of deoxynucleoside triphosphate (dNTP) mix ( $2.5 \mathrm{mM}$ each), and $0.5 \mu \mathrm{l}$ of Moloney murine leukemia virus reverse transcriptase (200 U/ $\mu \mathrm{l}$; Life Technologies, Inc.). The reaction mixture was incubated at $37^{\circ} \mathrm{C}$ for at least $1 \mathrm{~h}$.

The resulting cDNA was amplified by PCR using either degenerate or specific upstream and downstream primers. A total of $5 \mu \mathrm{l}$ of cDNA was mixed with $27 \mu \mathrm{l}$ of $\mathrm{H}_{2} \mathrm{O}, 4 \mu \mathrm{l}$ of $10 \times \mathrm{Taq}$ polymerase buffer (HT-Technologies Ltd., Cambridge, United Kingdom), $1 \mu \mathrm{l}$ of each primer $(100 \mathrm{ng} / \mu \mathrm{l}), 1 \mu \mathrm{l}$ of dNTPs $(2.5 \mathrm{mM}$ each), and $1 \mu \mathrm{l}$ of Taq polymerase ( $0.5 \mathrm{U} / \mu \mathrm{l}$; HT-Technologies Ltd.). Incubation was in a PTC 200 thermocycler (MJ Research Inc., Watertown, MA): $5 \mathrm{~min}$ at $95^{\circ} \mathrm{C}$, followed by 35 cycles of $30 \mathrm{~s}$ at $92^{\circ} \mathrm{C}, 30 \mathrm{~s}$ at $52^{\circ} \mathrm{C}$, and $45 \mathrm{~s}$ at $72^{\circ} \mathrm{C}$, and a final extension of amplification products for $10 \mathrm{~min}$ at $72^{\circ} \mathrm{C}$. Amplification products were analyzed for size and yield by electrophoresis on a $1 \%$ Trisacetate EDTA (TAE) agarose gel.

PCR primers. Initial cDNA synthesis and PCR amplification of the $3^{\prime}$ end of the SYSV, WoYSV, and OYDV genomic RNAs was done using P9502 as downstream primer (Table 1) and CPUP as a degenerate upstream primer (Table 1) derived from a highly conserved domain of the potyviral CP gene. This primer pair had previously been used successfully to amplify the $3^{\prime}$-terminal region of lettuce mosaic virus isolates (25) and other potyviruses (26).

The N-terminal CP-encoding region of SYSV and WoYSV RNAs was amplified using upstream primer SYS-UP and downstream primer SYS-DW (Table 1) derived from an alignment of the OYDV sequence (D73378) (23) and a sequence of the 3' end of the RNA of SYSV Ac127I as determined at BBA, Braunschweig. The Nterminal region of OYDV was amplified using upstream primer OYD-UP and downstream primer OYD-DW (Table 1), both derived from OYDV isolates sequenced at BBA, Braunschweig (34).

Cloning and sequencing of amplification products. Amplification products were purified from the reaction mixture using a PCR cleanup kit (Boehringer GmbH, Mannheim, Germany). The purified PCR fragment was ligated into a pGEM-T PCR cloning vector (Promega Corp., Madison, WI), and the ligation mixture was transformed to Escherichia coli JM109 highly competent cells (Promega Corp.), according to the manufacturer's instructions. Plasmids were isolated from recombinant $E$. coli by alkaline lysis and analyzed for the presence of the expected insert by restriction analysis using BamHI.

TABLE 1. Primers used for cDNA synthesis and polymerase chain reaction amplification of the $3^{\prime}$ end of the shallot yellow stripe virus, Welsh onion yellow stripe virus, and onion yellow dwarf virus genomic RNAs

\begin{tabular}{ll}
\hline Primer name & \multicolumn{1}{c}{ Primer sequence $^{\mathrm{a}}$} \\
\hline P9502 & 5'-GCGGATCCTTTTTTTTTTTTTTTT-3' \\
CPUP & 5'-TGAGGATCCTGGTGYATHGARAAYGG-3' \\
SYS-UP & 5'-GCAGGATCCAACACCRAGTTATGTGTC-3' \\
SYS-DW & 5'-TTCGGATCCATRTGAGCTTCCTTCGC-3' \\
OYD-UP & 5'-CTGGATCCGCAGTKCGATAYCAAG-3' \\
OYD-DW & 5'-CACGGATCCGYGCCATWATYTGTCTG-3' \\
\hline
\end{tabular}

${ }^{\mathrm{a}} \mathrm{R}=\mathrm{A}$ or $\mathrm{G}, \mathrm{Y}=\mathrm{C}$ or $\mathrm{T}, \mathrm{W}=\mathrm{A}$ or $\mathrm{T}, \mathrm{K}=\mathrm{T}$ or $\mathrm{G}$, and $\mathrm{H}=\mathrm{A}$ or $\mathrm{T}$ or $\mathrm{C}$. 
Plasmids containing an insert of the expected size were isolated from overnight cultures of recombinant bacteria using the Wizard miniprep DNA purification system (Promega Corp.) according to the manufacturer's instructions. Several purified plasmid DNAs were sequenced on an $\mathrm{ABI}$ automatic sequencer (Applied Biosystems, Inc., Foster City, CA) using standard M13 forward and reverse primers. Sequence data were compiled and analyzed using the UW-GCG (version 8) and the Lasergene (DNASTAR Inc., Madison, WI) software packages.

\section{RESULTS}

Serological properties. Purified preparations of SYSV Ac127I virions contained numerous flexuous, filamentous particles of $\sim 750 \mathrm{~nm}$, often in end-to-end aggregation. The antiserum raised against SYSV had a homologous titer of 1:1,024 in microprecipitin tests. To determine the serological relationships between SYSV Ac127I and WoYSV Af19I, as well as their serological affinities to other potyvirus isolates from shallot and Welsh onion and to the type and other isolates of OYDV and LYSV, decoration experiments were conducted by testing a range of potyvirus isolates with 10 antisera and one MAb to SYSV in all possible combinations (Table 2). All isolates from shallot and Welsh onion tentatively assigned to SYSV and WoYSV, respectively, reacted intermediately to strongly with the MAb and antiserum to SYSV Ac127I as well as with the three antisera supplied from Japan. However, these four antisera did not decorate or only weakly decorated particles of the OYDV and LYSV isolates, whereas MAb $1 \mathrm{H} 12$ failed to decorate particles of any OYDV and LYSV isolate. On the other hand, the three OYDV antisera gave stronger decorations in homologous combinations, but did not decorate or only weakly decorated SYSV and WoYSV particles and did not decorate the particles of the LYSV isolates. The three LYSV antisera used showed an intermediate to strong decoration of LYSV particles, but failed to decorate particles of SYSV, WoYSV, and OYDV isolates, except in one case in which a weak reaction was obtained.

Molecular properties. Sequencing of SYSV at BBA. The $3^{\prime}$ region of the SYSV Ac127I RNA was cloned using conventional oligo(dT)primed cDNA synthesis and cloning methods. A total of 1,145 nucleotides (nt) (without the poly(A) tail) of the 3' end of the SYSV Ac127I genome were determined (EMBL accession \#AJ223826).
It contained one large open reading frame (ORF) coding for a protein of 314 amino acids followed by a 3'-NTR of 197 nt. Alignment of the amino acid sequence of the putative protein with polyproteins of potyviruses revealed that the predicted sequence had high similarity with corresponding portions of the polyprotein of other potyviruses, starting at the C-terminal end of the nuclear inclusion protein $\mathrm{b}(\mathrm{NIb})$ and containing the entire $\mathrm{CP}$. The putative cleavage site of the SYSV NIa protease appeared to be Q56/A57 on the basis of the alignment. This prediction was supported by the presence of a DAAN motif, a variation of the DAGK motif (2), at six residues downstream from the putative cleavage site. The predicted CP is 258 amino acids with a calculated molecular mass of $29.5 \mathrm{kDa}$.

Restriction fragment length polymorphism (RFLP) and sequence analysis of SYSV and WoYSV at IPO-DLO. For elucidating the correct taxonomic position of WoYSV, the sequences of the CPencoding regions and the $3^{\prime}$-NTR of SYSV isolate Ac127I and WoYSV isolate Af19I were determined. Virus particles of SYSV Ac127I or WoYSV Af19I were trapped by immunocapture using the SYSV Ac127I antiserum. Subsequent RT-PCR experiments with primers P9502 and CPUP resulted in DNA fragments of approximately $650 \mathrm{bp}$ for both SYSV and WoYSV. To assess the possible relationship between SYSV and WoYSV, PCR fragments were subjected to RFLP analysis using several frequently cutting endonucleases (RsaI, MspI, AluI, and MseI). This analysis revealed clear differences in RFLP patterns for PCR products obtained for SYSV and WoYSV (data not shown).

PCR fragments obtained for the two virus isolates were cloned, and plasmid DNAs from recombinant $E$. coli were analyzed for the presence of the desired insert by digestion with BamHI, a site present at the $5^{\prime}$ end of the PCR primers used for amplification. For both SYSV and WoYSV, at least 10 recombinant plasmids were used as templates in a PCR experiment with primers P9502 and CPUP. Resulting DNA fragments were again subjected to RFLP analysis with the same enzymes used before. For all recombinant plasmids of SYSV and WoYSV, RFLP analysis of the PCR fragments gave RFLP patterns typical of each virus.

For SYSV and WoYSV, one clone each was selected for sequencing. For each clone, the largely overlapping DNA sequences resulting from the forward and reverse primers were combined. This resulted in DNA sequences of $645 \mathrm{nt}$ for SYSV and $643 \mathrm{nt}$

TABLE 2. Serological relationships among potyvirus isolates from Allium spp. as assessed by decoration experiments

\begin{tabular}{|c|c|c|c|c|c|c|c|c|c|c|c|}
\hline \multirow[b]{2}{*}{ Isolates and origins ${ }^{\mathrm{a}}$} & \multirow[b]{2}{*}{$\begin{array}{l}\text { Anti-SYSV } \\
\text { MAb 1H12 }\end{array}$} & \multicolumn{4}{|c|}{ Antisera to SYSVb } & \multicolumn{3}{|c|}{ Antisera to $\mathrm{OYDV}^{\mathrm{b}}$} & \multicolumn{3}{|c|}{ Antisera to LYSV ${ }^{b}$} \\
\hline & & $\begin{array}{c}\text { Ac127I } \\
\text { Netherlands }\end{array}$ & $\begin{array}{l}\text { WYDV } \\
\text { Japan }\end{array}$ & $\begin{array}{l}\text { OYDV } \\
\text { Fukami }\end{array}$ & $\begin{array}{l}\text { OYDV-O } \\
\text { Sako }\end{array}$ & $\begin{array}{c}510 \\
\text { Germany }\end{array}$ & $\begin{array}{c}\text { Ac41 } \\
\text { Netherlands }\end{array}$ & France & $\begin{array}{c}\text { L-BBA } \\
\text { Germany }\end{array}$ & $\begin{array}{c}512 \mathrm{G} \\
\text { Taiwan }\end{array}$ & $\begin{array}{c}\text { Aa22 } \\
\text { Netherlands }\end{array}$ \\
\hline \multicolumn{12}{|l|}{ SYSV } \\
\hline Ac127I, Indonesia (type) & $+++* c$ & $+++^{*}$ & +++ & ++ & +++ & + & + & + & + & - & - \\
\hline 642Sh, Thailand & ++ & +++ & ++ & ++ & ++ & - & + & + & - & - & - \\
\hline 318Sh, Taiwan & +++ & +++ & + & ++ & +++ & + & + & - & - & - & - \\
\hline \multicolumn{12}{|l|}{ WoYSV } \\
\hline Af19I, Indonesia (type) & ++ & +++ & ++ & +++ & +++ & - & ++ & + & - & - & - \\
\hline 7WO, Taiwan & +++ & +++ & ++ & +++ & +++ & - & + & + & - & - & - \\
\hline 198WO, Taiwan & +++ & +++ & ++ & +++ & +++ & + & + & - & - & - & - \\
\hline \multicolumn{12}{|l|}{ OYDV } \\
\hline Ac41, Netherlands (type) & - & + & + & + & + & +++ & $+++^{*}$ & +++ & - & - & - \\
\hline 510 , Germany & - & - & - & + & + & $+++*$ & +++ & +++ & - & - & - \\
\hline 7470, Sudan & - & + & - & - & + & +++ & +++ & ++ & - & - & - \\
\hline \multicolumn{12}{|l|}{ LYSV } \\
\hline Aa22, Netherlands (type) & - & - & - & - & - & - & - & - & +++ & ++ & ++ \\
\hline L-BBA, Germany & - & - & - & - & - & - & - & + & $++^{*}$ & ++ & ++ \\
\hline 510L, Singapore & - & + & - & - & - & - & - & - & +++ & ++ & ++ \\
\hline
\end{tabular}

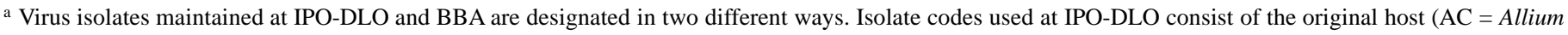
cepa, $\mathrm{Af}=$ A. fistulosum, and $\mathrm{Aa}=$ A. ampeloprasum $)$ and a number, whereas those used at $\mathrm{BBA}$ consist of a number and the original host $(\mathrm{L}=1$ leek, $\mathrm{O}=$ onion, $\mathrm{Sh}=$ shallot, and $\mathrm{WO}=$ Welsh onion).

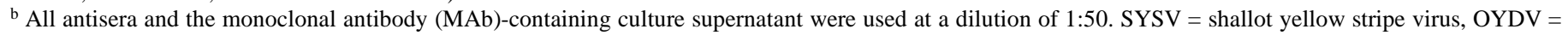
onion yellow dwarf virus, LYSV = leek yellow stripe virus, and WoYSV $=$ Welsh onion yellow stripe virus.

c Decoration was scored as strong $(+++)$, intermediate $(++)$, weak $(+)$, and nondetectable $(-) ; *$ homologous reactions. 
for WoYSV, consisting of $447 \mathrm{nt}$ of the CP-encoding sequence and a 3'-NTR of 197 and $195 \mathrm{nt}$, respectively (excluding the poly(A) tail).

Alignment of the partial CP amino acid and complete 3 '-NTR nucleotide sequences of SYSV Ac127I determined at IPO-DLO with those determined at BBA revealed, as expected, high levels of sequence identity (100 and $99.5 \%$, respectively). Surprisingly, however, a very high level of identity was also observed between SYSV and WoYSV for their partial CP amino acid and 3 '-NTR sequences of (98 and $89 \%$, respectively). This was unexpected, because SYSV and WoYSV seemed to be distinct potyviruses based on the RFLP analysis of their PCR fragments. Closer examination of the sequence alignments revealed that, in the amplified fragments, a total of eight sites, present for the four restriction enzymes selected for the RFLP analysis, revealed nucleotide differences in the recognition sequences (Fig. 1), resulting in different RFLP patterns for SYSV and WoYSV.

Sequence comparison of SYSV and WoYSV with OYDV. SYSV and WoYSV sequences were compared with sequences available in the EMBL database. Surprisingly, a striking identity was found with a potyvirus sequence from Wakegi onion deposited as a Japanese OYDV isolate under accession \#D73378. The C-terminal portion of the CP sequences of SYSV and WoYSV showed amino acid sequence identities of 97 and $98 \%$, respectively. For the 3'-NTR

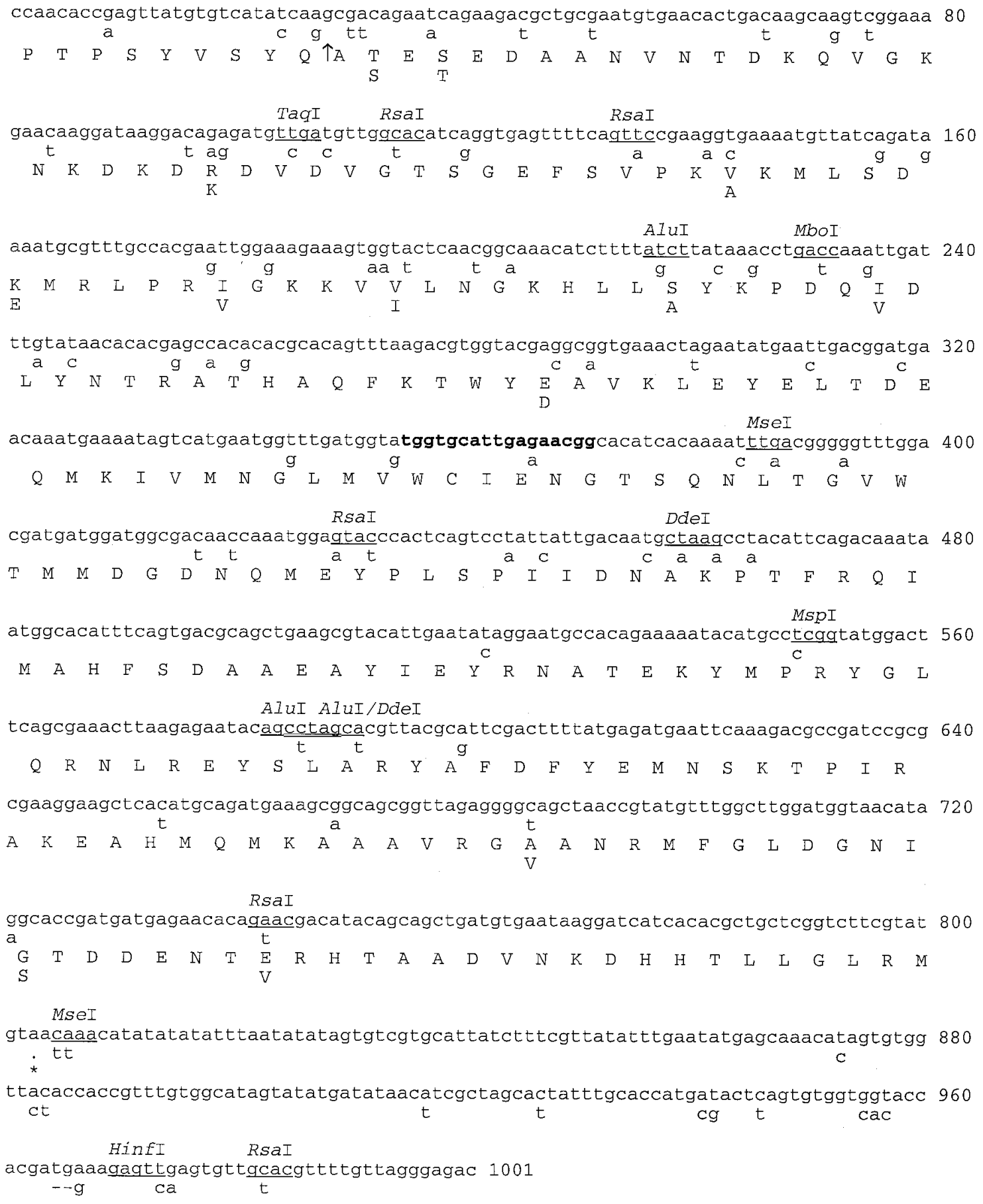

Fig. 1. Nucleotide (lower case letters) and deduced amino acid sequences (upper case letters) of the $3^{\prime}$ end of the shallot yellow stripe virus (SYSV) Ac127I genome. Nucleotides and deduced amino acid residues of Welsh onion yellow stripe virus (WoYSV) Af19I differing from those of SYSV Ac127I are indicated below the sequences. The putative cleavage site between the nuclear inclusion protein $b$ and coat protein is marked by an arrow. The annealing site of the degenerate potyvirus primer CPUP is in bold. Recognition sites for common restriction endonucleases that differ between the sequences of SYSV and WoYSV due to differences in nucleotide sequence are underlined. 
region, nucleotide sequence identities were 87 and 93\%, respectively. These high levels of sequence identities among SYSV, WoYSV, and the Japanese OYDV sequences suggested a close relationship among these viruses.

To gain more insight into the relationship of SYSV and WoYSV to the Japanese OYDV isolate, the region encoding the CP N-termini of SYSV Ac127I and WoYSV Af19I was amplified using the primer pair SYS-UP/SYS-DW. In addition, the entire CP-encoding region and 3'-NTR of the RNA of the type isolate of OYDV Ac41 (8) was amplified using the primer combinations P9502-CPUP and OYD-UP-OYD-DW. PCR experiments with these primers on cDNA generated with P9502 for both SYSV and WoYSV resulted in DNA fragments of approximately $700 \mathrm{bp}$, and for OYDV, in DNA fragments of 480 and $650 \mathrm{bp}$. All fragments were purified, cloned in pGEM-T vectors, and sequenced. Sequence data were combined with data previously obtained. This resulted in a total of 1,011 nt for SYSV Ac127I (EMBL accession \#Y11747), 1,009 nt for WoYSV Af19I (EMBL accession \#Y11748) and 1,003 nt for OYDV Ac41 (EMBL accession \#Y11826), all of which contained the complete CP gene and 3'-NTR of these viruses.

The sequences of SYSV and WoYSV both encode a CP of 258 amino acids. The cleavage site between the NIb and CP gene is most likely located at the Q/A dipeptide for SYSV and WoYSV (Fig. 1). Alignment of complete CP amino acid and 3'-NTR nucleotide sequences of SYSV, WoYSV, and Japanese OYDV showed identity levels of $\sim 95 \%$ for the CP and $88 \%$ for the $3^{\prime}$-NTR. An alignment of these sequences with OYDV Ac41 and a LYSV isolate from leek (deposited by J. Schubert, EMBL accession \#X89711) revealed much lower levels of identities averaging 73 and $68 \%$ for the CP and 32 and $27 \%$ for the $3^{\prime}$-NTR, respectively. Results of the alignments are summarized in Table 3.

Sequence comparisons of SYSV isolates. The CP and 3'-NTR sequences of the type isolates of SYSV and WoYSV were compared with those of the Wakegi-type isolates reported by Tsuneyoshi et al. (24). Multiple alignments of these sequences showed that their $\mathrm{CP}$ amino acid and $3^{\prime}$-NTR nucleotide sequence identities varied from 95 to $100 \%$ and from 85 to $100 \%$, respectively. Moreover, both the CP amino acid and 3'-NTR nucleotide sequences of the three shallot isolates were more closely related to one another and different from those of the five isolates originating from nonshallot hosts such as Welsh onion, Wakegi onion, and rakkyo.

Detailed comparison of the $\mathrm{CP}$ amino acid sequences revealed that the $\mathrm{CP}$ core domain contained six amino acid positions that were identical in the three shallot isolates but distinct from the corresponding residues in the five nonshallot isolates (Fig. 2A). With the exception of $\mathrm{CP}$ amino acid position 2, there were no isolate group-specific differences in the 24 amino-terminal amino acids of the SYSV isolates.

Alignment of the $3^{\prime}$-NTR sequences also revealed a number of nucleotide positions in which the shallot isolates differed from the nonshallot isolates (Fig. 2B). Using the Structure Analysis of RNA (STAR) program of Abrahams et al. (1), a search for potential secondary structures in the 3'-NTR of all SYSV isolates suggested

TABLE 3. Pairwise percent identities among coat protein amino acid sequences (above diagonal) and 3'-nontranslated region nucleotide sequences (below diagonal) of shallot yellow stripe virus (SYSV) Ac127I, Welsh onion yellow stripe virus (WoYSV) Af19I, Wakegi yellow dwarf virus (WYDV), onion yellow dwarf virus (OYDV) Ac41, and leek yellow stripe virus (LYSV)

\begin{tabular}{lccccc}
\hline & $\begin{array}{c}\text { SYSV } \\
\text { Ac127I }\end{array}$ & $\begin{array}{c}\text { WoYSV } \\
\text { Af19I }\end{array}$ & WYDV $^{\mathrm{a}}$ & $\begin{array}{c}\text { OYDV } \\
\text { Ac41 }\end{array}$ & $\begin{array}{c}\text { LYSV } \\
(\text { X89711) }\end{array}$ \\
\hline SYSV Ac127I & $\ldots$ & 95 & 95 & 74 & 69 \\
WoYSV Af19I & 89 & $\ldots$ & 97 & 73 & 68 \\
WYDV $^{\mathrm{a}}$ & 86 & 93 & $\ldots$ & 74 & 57 \\
OYDV Ac41 & 33 & 31 & 31 & $\ldots$ & 58 \\
LYSV (X89711) & 27 & 27 & 28 & 25 & $\ldots$ \\
\hline
\end{tabular}

a Sequence (accession \#D73378) erroneously assigned to onion yellow dwarf virus, but later referred to as Wakegi yellow dwarf virus. the presence of three possible hairpin-loop structures (Fig 2B). Only the 3'-proximal potential hairpin-loop structure was located in a region where major differences between shallot and nonshallot isolates occurred (Fig. 2B). In particular, the three nucleotides $\mathrm{C} / \mathrm{TAC}$ of the nonshallot isolates, located in the loop of this potential hairpin-loop structure, were replaced by GGT in the shallot isolates that, in addition, had an insertion of two nucleotides (TA) just $3^{\prime}$ of this potential stem-loop structure.

\section{DISCUSSION}

Results of detailed host range and serological studies by Van Dijk (28) on isolates from a large number of Allium spp. suggested that, in addition to OYDV and LYSV, two distinct new potyviruses might exist for which the names WoYSV and SYSV were proposed. WoYSV differed from SYSV in infecting rakkyo ( $A$. chinense) and Welsh onion (A. fistulosum), in inducing local necrotic reactions in $C$. amaranticolor and $C$. quinoa, and in its weak reaction with a Dutch antiserum to OYDV (1:3 to 1:10 dilution). The production of an antiserum and MAb to SYSV has now permitted a further serological comparison of the type isolates of SYSV and WoYSV with other potyvirus isolates from shallot and Welsh onion as well as with the type isolates of OYDV and LYSV (Table 2).

Based on the serological data presented, the shallot and Welsh onion potyvirus isolates studied appear to be serologically closely related to one another, as they were serologically indistinguishable under the conditions of the decoration experiments using antisera diluted 1:50. This observation, and the frequently observed weak decoration reactions obtained in heterologous combinations between the OYDV antisera and the isolates from shallot and Welsh onion as well as in reciprocal combinations, suggested that SYSV and WoYSV isolates are serologically closely related to, but clearly distinct from, OYDV. The SYSV MAb $1 \mathrm{H} 12$ reacted only with the shallot and Welsh onion isolates, not with any of the OYDV and LYSV isolates, corroborating the serological similarity of SYSV and WoYSV and their discrimination from OYDV and LYSV. Since the LYSV antisera and isolates generally did not react in heterologous combinations with OYDV, SYSV, and WoYSV, the serological relationship of these isolates to LYSV is distant. These results indicate that SYSV and WoYSV are strains of the same virus that, in accordance with the earlier conclusion by van Dijk (28), is clearly distinct from LYSV and OYDV. Most interestingly, the three Japanese antisera to Welsh onion isolates of potyviruses referred to as OYDV (Fukami), OYDV-O, and WYDV reacted strongly with SYSV and WoYSV isolates only and showed no or only weak reactions with OYDV isolates, including the type isolate Ac41 (8). This suggested that the virus isolates used to raise the Japanese antisera were inappropriately identified and, in fact, were isolates of SYSV and WoYSV.

For potyviruses, the sequences of the $3^{\prime}$-NTR and the N-terminal region of the $\mathrm{CP}$ are considered virus specific, and these sequences have been extensively used for the classification of potyviruses and potyvirus strains $(11,22)$. The SYSV Ac127I sequence determined independently both at IPO-DLO and BBA differed over 1,001 nt only in three nucleotides: one each in the NIb, CP, and 3'NTR regions. Only one of these resulted in an amino acid exchange (T/K) at position 96 in the CP. When the $3^{\prime}$ end of the WoYSV Af19I RNA was compared with that of SYSV Ac127I, CP amino acid, and 3'-NTR, sequence identities of 95 and $89 \%$, respectively, were observed, confirming their classification as two strains of the same virus as already revealed by the decoration results. The observed levels of identity clearly met the criteria for considering SYSV and WoYSV as distinct strains of the same potyvirus species (22). Surprisingly, the CP amino acid sequences of SYSV and WoYSV also showed identities of 95 and 97\%, respectively, with an OYDV sequence (EMBL accession \#D73378) that Tsuneyoshi et al. (24) later referred to as WYDV. Since the IPO-DLO plant virus collection holds type isolates of all potyviruses from Allium 
spp. including OYDV Ac41 $(6,8)$, this enabled us to clarify the precise taxonomic relation of WYDV to OYDV. After sequencing the 3'-terminal RNA region of the OYDV type isolate Ac41, comparison of this sequence with that of WYDV, SYSV, and WoYSV revealed $\mathrm{CP}$ amino acid and $3^{\prime}$-NTR sequence identities ranging from only 72.8 to $74.3 \%$ and 30.8 to $33.2 \%$, respectively. This indicated that WYDV, SYSV, and WoYSV are isolates of a potyvirus that is distinct from OYDV. Furthermore, a comparison of the CP and 3'-NTR sequences of the type isolates of SYSV, WoYSV, and OYDV with the sequences of the Wakegi-type isolates of OYDV described by Tsuneyoshi et al. (24) clearly showed that the latter are all clearly distinct from OYDV and very closely related to the type isolates of SYSV and WoYSV.
The conclusion drawn from the sequence comparison of SYSV Ac127I and WoYSV Af19I was not in agreement with the conclusion from the RFLP analysis of PCR products obtained with the degenerate potyvirus primers. The use of four different restriction endonucleases showed quite distinct RFLP patterns for SYSV and WoYSV. Only when sequence data became available did it become clear that a limited number of nucleotide differences between SYSV and WoYSV accounted for this difference. RFLP analysis of PCR products has been described as a quick and convenient way to discriminate viruses and virus strains $(3,12,14,15)$. However, our results showed that RFLP data, even when using multiple restriction endonucleases, should be interpreted with caution and that sequence analysis may be a more reliable means of classifying plant viruses.

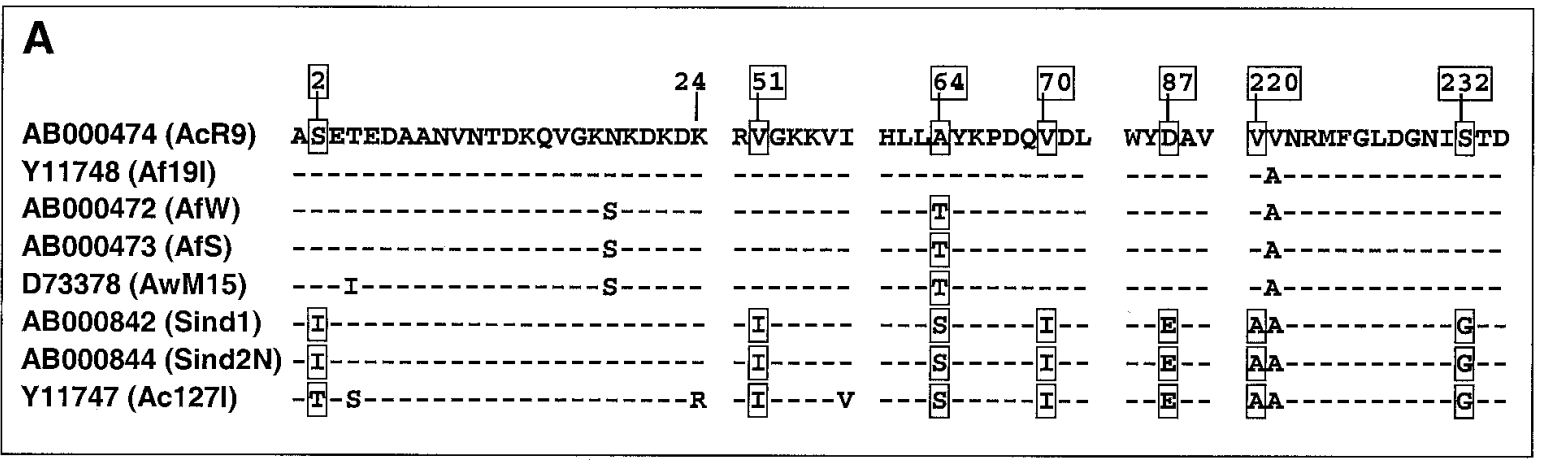

B

\begin{tabular}{|c|c|c|}
\hline & Hairpin loop I & \\
\hline AB000472 (AfW) & TAAACATATATAT TT .TTAATATATAGTGTCGTGCATTATCTTTCGTTATATTTGAATATGAGCAA & 65 \\
\hline AB000473 (AfS) & 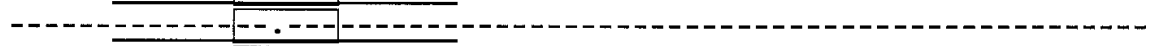 & 65 \\
\hline AB000474 (AcR9) & C-1- & 66 \\
\hline Y11748 (Af19l) & 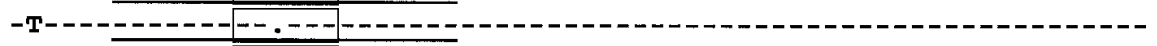 & 65 \\
\hline D73378 (AwM15) & C---1- & 64 \\
\hline AB000842 (Sind1) & 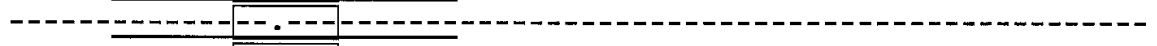 & 65 \\
\hline$A B 000844($ Sind2N) & 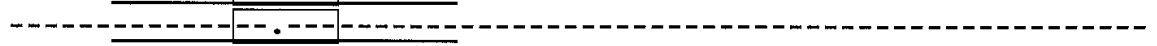 & 65 \\
\hline Y11747 (Ac127I) & 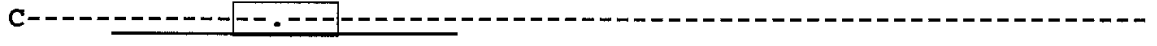 & 65 \\
\hline & Hairpin loop II & \\
\hline AB000472 (AfW) & ACACAGTGTGGTTACACCACCGTTTGTGGCATAGTATATGATATAACTTCGCTAGCATTATTTGCA & 131 \\
\hline AB000473 (AfS) & 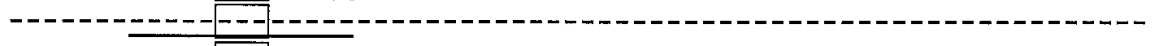 & 131 \\
\hline AB000474 (AcR9) & 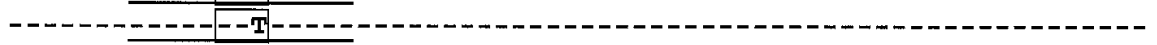 & 132 \\
\hline Y11748 (Af19l) & 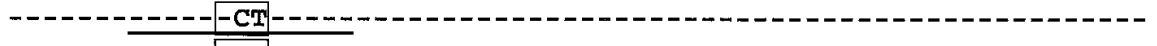 & 131 \\
\hline D73378 (AwM15) & 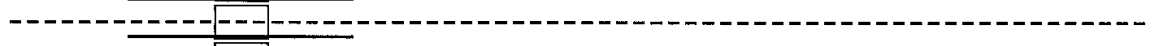 & 130 \\
\hline AB000842 (Sind1) & 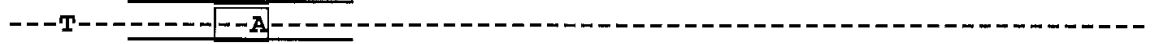 & 131 \\
\hline AB000844 (Sind2N) & 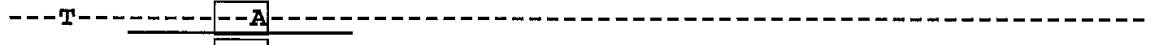 & 131 \\
\hline Y11747 (Ac127I) & - & 131 \\
\hline & Hairpin loop III & \\
\hline AB000472 (AfW) & CCATGCGACTTAGTGTGGTCACACCACGA. . GAAGAGTCAAGTGTTGTACGTTTTGTTAGGGAGAC & 195 \\
\hline AB000473 (AfS) & 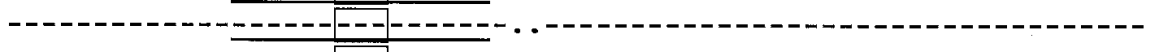 & 195 \\
\hline AB000474 (AcR9) & 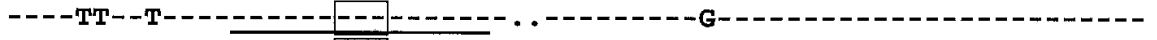 & 196 \\
\hline Y11748 (Af19l) & - & 195 \\
\hline D73378 (AwM15) & 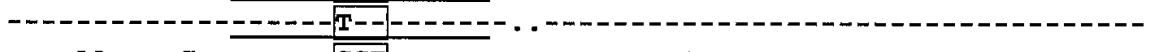 & 194 \\
\hline AB000842 (Sind1) & 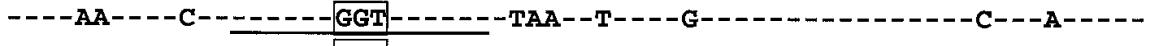 & 197 \\
\hline AB000844 (Sind2N) & 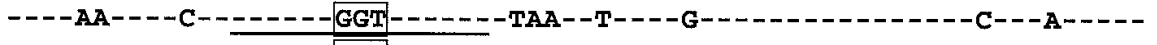 & 197 \\
\hline Y11747 (Ac127I) & 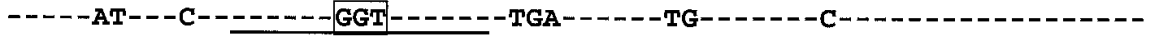 & 197 \\
\hline
\end{tabular}

Fig. 2. Multiple alignments of A, shallot yellow stripe virus (SYSV) coat protein (CP) amino acid and B, $3^{\prime}$-nontranslated region ( $3^{\prime}$-NTR) nucleotide sequences. A, Only the $24 \mathrm{~N}$-terminal CP amino acids and CP amino acid domains are shown in which residues discriminating shallot from nonshallot isolates were identified. Discriminating amino acid residues and their relative position within the SYSV CP are blocked. B, Loop sequences of predicted hairpin-loop structures in the 3'-NTR are indicated by boxes, potential hairpin-loop regions are underlined, and gaps resulting from the multiple alignment are marked by dots. Isolate designations are EMBL accession numbers and according to Tsuneyoshi et al. (24) and this paper. The original host plants from which sequences were obtained are rakkyo (AcR9), Welsh onion (Af19I, AfW, and AfS), Wakegi onion (AwM15), and shallot (Sind1, Sind2N, and Ac127I), as indicat ed in parentheses. 
Comparison of the CP amino acid and 3 '-NTR nucleotide sequences of SYSV and WoYSV with those of the Wakegi-type isolates of OYDV (24) revealed a grouping of isolates according to plant species from which the SYSV sequence was obtained. The differences between the two groups resided chiefly in six amino acid residues of the $\mathrm{CP}$ core and in a strikingly distinct putative hairpin-loop present at the $3^{\prime}$ end of the $3^{\prime}$-NTR (Fig. 2A and B). For potato virus $\mathrm{Y}$, the classification of isolates as strain groups based on biological and CP properties was supported by differences in loop sequences of potential hairpin-loop structures in the 3 '-NTR (27). Additional circumstantial and experimental evidence indicated that differences in CP amino acid and 3 '-NTR nucleotide sequences of potyvirus isolates may be biologically significant (17, $21,22,27)$. Therefore, it is tempting to speculate that at least some of the observed differences in the amino acid sequences of the $\mathrm{CP}$ core domain and in the nucleotide sequences of the 3'-NTR might be associated with the proposed grouping of SYSV isolates. However, more host range and sequence data on further SYSV isolates, both from shallot and nonshallot hosts, will be required to substantiate the proposed grouping of host-specialized strains of SYSV.

Virus identification in Allium spp., especially the vegetatively propagated species, is complicated by the frequency of mixed infections and infections by several members of the genera Potyvirus and Carlavirus and the yet-unclassified mite-borne filamentous viruses, as well as by host-adapted and serologically deviating strains of these viruses $(4,5,9,28,29,32,37)$. With the advent of molecular plant virology, many researchers produced sequence information and proposed several new virus names without proper identification of their virus isolates, using available type isolates of, and antisera to, the viruses already formally described. This also applies to recent research on potyviruses of Allium spp., although type isolates of and antisera to OYDV and LYSV, the two major potyviruses infecting onion, shallot, and garlic in many parts of the world, have been available for many years $(6,8,10)$. Proper biological and serological identification of virus isolates is a prerequisite to molecular characterization. Only this allows identification of the molecular determinants of the biological properties of the virus isolates.

In conclusion, the results of our serological and molecular studies suggest that East Asian potyvirus isolates from shallot (A. cepa var. ascalonicum), rakkyo (A. chinense), Welsh onion (A. fistulosum), and Wakegi onion (A. wakegi Araki, a hybrid of $A$. cepa $\times A$. fistulosum) (13) are predominantly isolates of one virus. For priority reasons, all of these isolates including the Wakegi-type isolates reported by Tsuneyoshi et al. (24) should be referred to as SYSV. The SYSV isolates from Allium spp. other than shallot should be designated as the Welsh onion strain of SYSV (SYSV-Wo).

\section{ACKNOWLEDGMENTS}

We thank J. Vink (IPO-DLO), H. Lot (INRA, Montfavet France), M. Fukami (Chiba, Japan), S. T. Ohki (Osaka, Japan), and S. Sumi (Hiroshima, Japan) for providing antisera; H. Huttinga for critically reading the manuscript; M. Schönfelder for his assistance in sequence analysis; and S. Bonse for technical assistance in decoration experiments.

\section{LITERATURE CITED}

1. Abrahams, J. P., Van den Berg, M., Van Batenburg, E., and Pleij, C. 1990. Prediction of RNA secondary structure, including pseudoknotting, by computer simulation. Nucleic Acids Res. 18:3035-3044.

2. Atreya, P. L., Lopez-Moya, J. J., Chu, M., Atreya, C. D., and Pirone, T. P. 1995. Mutational analysis of the coat protein N-terminal amino acids involved in potyvirus transmission by aphids. J. Gen. Virol. 76:265-270.

3. Barbara, D. J., Morton, A., Spence, N. J., and Miller, A. 1995. Rapid differentiation of closely related isolates of two plant viruses by polymerase chain reaction and restriction fragment length polymorphism analysis. J. Virol. Methods 55:121-131.

4. Barg, E., Lesemann, D.-E., Vetten, H. J., and Green, S. K. 1994. Identification, partial characterization and distribution of viruses infecting
Allium crops in south and south-east Asia. Acta Hortic. 358:251-258.

5. Barg, E., Lesemann, D.-E., Vetten, H. J., and Green, S. K. 1997. Viruses of Alliums and their distribution in different Allium crops and geographical regions. Proc. First Int. Symp. Edible Alliaceae, Mendoza, Argentina. Acta Hortic. 433:607-616.

6. Bos, L. 1976. Onion yellow dwarf virus. CMI (Commonw. Mycol. Inst.)/AAB (Assoc. Appl. Biol.) Descriptions of Plant Viruses. No. 158. Kew, Surrey, England.

7. Bos, L. 1983. Viruses and virus diseases of Allium species. Acta Hortic. 127:11-29.

8. Bos, L., Huijberts, N., Huttinga, H., and Maat, D. Z. 1978. Leek yellow stripe virus and its relationships to onion yellow dwarf virus; characterization, ecology and possible control. Neth. J. Plant Pathol. 84:185-204.

9. Delecolle, B., and Lot, H. 1981. Viroses de l'ail: I. Mise en évidence et essais de caractérisation par immunoélectromicroscopie d'un complexe de trois virus chez différentes populations d'ail atteintes de mosaique. Agronomie 1:763-769.

10. Delecolle, B., Lot, H., and Michel, M.-J. 1985. Application of ELISA for detecting onion yellow dwarf virus in garlic and shallot seed and plants. Phytoparasitica 13:266-267.

11. Frenkel, M. J., Ward, C. W., and Shukla, D. D. 1989. The use of 3' noncoding nucleotide sequences in the taxonomy of potyviruses: Applications to watermelon mosaic virus 2 and soybean mosaic virus-N. J. Gen. Virol. 70:2775-2783.

12. Gillings, M., Broadbent, P., Indsto, J., and Lee, R. 1993. Characterisation of isolates and strains of citrus tristeza closterovirus using restriction analysis of the coat protein gene amplified by the polymerase chain reaction. J. Virol. Methods 44:305-317.

13. Hanelt, P. 1990. Taxonomy, evolution and history. Pages 1-26 in: Onions and Allied Crops. Volume I. Botany, Physiology and Genetics. H. D. Rabinowitch and J. L. Brewster, eds. CRC Press Inc., Boca Raton, FL.

14. Langeveld, S. A., Dore, J.-M., Memelink, J., Derks, A. F. L. M., Van der Vlugt, C. I. M., Asjes, C. J., and Bol, J. F. 1991. Identification of potyviruses using the polymerase chain reaction with degenerate primers. J. Gen. Virol. 72:1531-1541.

15. Liu, H.-J., Giambrone, J. J., and Dormitorio, T. 1994. Detection of genetic variations in serotype I isolates of infectious bursal disease virus using polymerase chain reaction and restriction endonuclease analysis. J. Virol. Methods 48:281-291.

16. Maiss, E., Breyel, E., Brisske, A., and Casper, R. 1988. Molecular cloning of cDNA complementary to the RNA genome of plum pox virus (PPV). J. Phytopathol. 122:222-241.

17. Rodríguez-Cerezo, E., Gamble Klein, P., and Shaw, J. J. 1991. A determinant of disease symptom severity is located in the $3^{\prime}$-terminal noncoding region of the RNA of a plant virus. Proc. Natl. Acad. Sci. U.S.A. 88:9863-9867.

18. Sako, I., Nakasone, W., Okada, K., Ohki, S. T., Osaki, T., and Inouye, T. 1991. Yellow streak of rakkyo (Allium chinense G. Don), a newly recognized disease caused by garlic latent virus and onion yellow dwarf virus. Ann. Phytopathol. Soc. Jpn. 57:65-69.

19. Sambrook, J., Fritsch, E. F., and Maniatis, T. 1989. Molecular Cloning: A Laboratory Manual. 2nd ed. Vol. 1, 2, and 3. Cold Spring Harbor Laboratory Press, Cold Spring Harbor, NY.

20. Sanger, F., Nicklen, S., and Coulson, A. R. 1977. DNA sequencing with chain-terminating inhibitors. Proc. Natl. Acad. Sci. U.S.A. 74:5463-5467.

21. Shukla, D. D., Frenkel, M. J., and Ward, C. W. 1991. Structure and function of the potyvirus genome with special reference to the coat protein coding region. Can. J. Plant Pathol. 13:178-191.

22. Shukla, D. D., Ward, C. W., and Brunt, A. A. 1994. The Potyviridae. CAB International, Wallingford, United Kingdom.

23. Tsuneyoshi, T., Ikeda, Y., and Sumi, S. 1997. Nucleotide sequences of the 3 '-terminal region of onion yellow dwarf isolates from Allium plants in Japan. Virus Genes 15:73-77.

24. Tsuneyoshi, T., Matsumi, T., Natsuaka, K. T., and Sumi, S. 1998. Nucleotide sequence analysis of virus isolates indicates the presence of three potyvirus species in Allium plants. Arch. Virol. 143:97-113.

25. Van der Vlugt, R. A. A., Berendsen, M., and Koenraadt, H. 1997. Immunocapture reverse transcriptase PCR for the detection of lettuce mosaic virus. Pages 185-191 in: Seed Health Testing. Progress Towards the 21st Century. J. D. Hutchins and J. C. Reeves, eds. CAB International, Wallingford, United Kingdom.

26. Van der Vlugt, R. A. A., and Bouwen, I. 1997. Identification of potyviruses infecting Alstroemeria. Pages 465-467 in: Diagnosis and Identification of Plant Pathogens. H.-W. Dehne, G. Adam, M. Diekmann, J. Frahm, A. Mauler-Machnik, and P. Van Halteren, eds. Kluwer Academic Publishers, Dordrecht, the Netherlands.

27. Van der Vlugt, R. A. A., Leunissen, J., and Goldbach, R. W. 1993. Taxonomic relationships between potato virus $\mathrm{Y}$ isolates based on detailed comparisons of the viral coat proteins and 3 '-nontranslated regions. 
Arch. Virol. 131:361-375.

28. Van Dijk, P. 1993. Survey and characterization of potyviruses and their strains of Allium species. Neth. J. Plant Pathol. 99:1-48.

29. Van Dijk, P. 1993. Carlavirus isolates from cultivated Allium species represent three viruses. Neth. J. Plant Pathol. 99:233-257.

30. Van Dijk, P., and Sutarya, R. 1992. Virus survey of garlic, shallot and Welsh onion in Java, Indonesia. Internal communication of the DLO Centre for Plant Breeding and Reproduction Research, Wageningen, the Netherlands.

31. Van Dijk, P., and Sutarya, R. 1992. Virus diseases of garlic, shallot and Welsh onion in Java, Indonesia, and prospects for their control. Onion Newsl. Trop. 4:57-61.

32. Van Dijk, P., and Van der Vlugt, R. A. A. 1994. New mite-borne virus isolates from rakkyo, shallot and wild leek species. Eur. J. Plant Pathol. 100:269-277.

33. Van Dijk, P., Verbeek, M., and Bos, L. 1991. Mite-borne virus isolates from cultivated Allium species, and their classification into two new rymoviruses in the family Potyviridae. Neth. J. Plant Pathol. 97:381399.

34. Vetten, H. J., Butgereitt, A., and Winter, S. 1997. Differentiation of Allium potyviruses by polymerase chain reaction. Pages $469-471$ in: Diagnosis and Identification of Plant Pathogens. H.-W. Dehne, G. Adam, M. Diekmann, J. Frahm, A. Mauler-Machnik, and P. Van Halteren, eds. Kluwer Academic Publishers, Dordrecht, the Netherlands.

35. Vetten, H. J., Lesemann, D.-E., and Allen, D. J. 1987. Occurrence of potyvirus and potexvirus infections in black bryony (Tamus communis L.) in Devon, U.K. Plant Pathol. 36:492-498.

36. Walkey, D. G. A. 1990. Virus diseases. Pages 191-212 in: Onions and Allied Crops, Vol. II. H. D. Rabinowitch and J. L. Brewster, eds. CRC Press Inc., Boca Raton, FL.

37. Walkey, D. G. A., Webb, M. J. W., Bolland, C. J., and Miller, A. 1987. Production of virus-free garlic (Allium sativum L.) by meristem-tip culture. J. Hortic. Sci. 62:211-220. 